\title{
PENSAMENTO DECOLONIAL FEMINISTA DO SUL: UMA EXPERIÊNCIA DE EDUCAÇÃO POPULAR A PARTIR DE NARRATIVAS DE MULHERES CAMPONESAS
}

\author{
SOUTHERN FEMINIST DECOLONIAL THINKING: AN EXPERIENCE \\ OF POPULAR EDUCATION BASED ON THE NARRATIVES OF \\ PEASANT WOMEN
}

\author{
Márcia Alves da Silva \\ Pós-Doutora em Educação pela PUC/RS \\ Docente do PPG em Educação da UFPel \\ Pelotas, RS - Brasil \\ profa.marciaalves@gmail.com.
}

\begin{abstract}
Resumo: Este texto aborda alguns aspectos que integraram estudos de Pós-Doutoramento na área de Educação, conduzidos pela autora, e tem como objetivo sistematizar teoricamente uma experiência de educação popular baseada na implementação de oficinas que foram realizadas com mulheres camponesas assentadas do Sul do Brasil, participantes do Movimento dos Trabalhadores e Trabalhadoras Rurais Sem Terra (MST). Essa experiência se articula na construção de um pensamento decolonial feminista latino-americano na área de Educação, iniciativa que não se coloca de forma isolada, mas compondo amplo leque de possibilidades, tanto políticas quanto investigativas. Dessa forma, o referencial teórico adotado se localiza no campo do pensamento feminista, compreendendo a decolonialidade aplicada à questão de gênero na América Latina e tendo como metodologia a coleta de dados empíricos por meio de narrativas autobiográficas, onde afloram as narrativas (auto)biográficas das mulheres do Sul, encaminhando-se na construção de um pensamento que coloca em xeque o conhecimento androcêntrico e eurocêntrico no qual a ciência moderna se baseou.
\end{abstract}

Palavras-chave: Brasil. Educação popular. Feminismo latino-americano. Mulheres camponesas. Movimentos sociais do campo.

\begin{abstract}
This text addresses some aspects that integrated Postdoctoral studies in the Education area, conducted by the author, and aims to theoretically systematize a popular education experience based on the implementation of workshops that were held with rural women from the south of Brazil, participants of the Landless Rural Workers Movement (MST). This experience is articulated in the construction of a Latin American feminist decolonial thought in the area of Education, an initiative that is not put in a isolation way, but composes a wide range of possibilities, both political and investigative. Thus, the theoretical frame adopted is located in the field of feminist thought, including the decoloniality applied to the gender issue in Latin America and using as methodology the collection of empirical data through autobiographical narratives, where the (self) biographical narratives of south women emerge, moving towards the construction of a thought that puts in check the androcentric and eurocentric knowledge on which modern science was based.
\end{abstract}

Keywords: Brazil. Popular education. Latin american feminism. Peasant women. Rural social movements.

\section{Para citar - (ABNT NBR 6023:2018)}

SILVA, Márcia Alves da. Pensamento decolonial feminista do Sul: uma experiência de educação popular a partir de narrativas de mulheres camponesas. Eccos - Revista Cientifica, São Paulo, n. 54, p. 1-17, e17322, jul./set. 2020. Disponível em: https://doi.org/10.5585/eccos.n54.17322. 


\section{Introdução}

A superação da colonialidade do poder e do conhecimento apresenta-se como um problema desafiador a ser enfrentado pela ciência. Conforme Quijano (2005), a colonialidade é o resultado de um padrão de conhecimento alicerçado numa estrutura de poder que tende a fundamentar o eurocentrismo. Essa estrutura de poder se desenvolveu baseada no processo histórico de colonização pelo qual se desenvolveu (e ainda se desenvolve) uma tendência de menosprezo aos conhecimentos e saberes das populações latinas que foram colonizadas. A ciência também se construiu com base nesse pensamento. No caso dos saberes das mulheres latino-americanas, esse processo de menosprezo ainda foi mais intenso, pois, conforme Segato (2018), a intervenção colonial, tanto no passado como no presente, tem a característica de diminuir tudo o que diz respeito às mulheres. Para ela,

\footnotetext{
El término minorización hace referencia a la representación y a la posición de las mujeres en el pensamiento social; minorizar alude aquí a tratar a la mujer como "menor" y también a arrinconar sus temas al ámbito de lo íntimo, de lo privado, y, en especial, de lo particular, como "tema de minorias" y, en consecuencia, como tema "minoritario". (SEGATO, 2018, p. 99)
}

Esse texto trata de uma experiência acadêmica que tem a intencionalidade de colaborar para a construção de uma educação popular feminista latino-americana que incorpore as questões de gênero, tendo como ponto de partida a proposta pedagógica advinda da educação popular em diálogo com o feminismo, baseada em narrativas coletadas em oficinas de produção artesanal realizadas com mulheres camponesas assentadas que participam do Movimento de Trabalhadores e Trabalhadoras Rurais Sem Terra (MST) do município de Pinheiro Machado, estado do Rio Grande do Sul, Brasil.

Mediante a implantação de cursos de artesanato para as envolvidas, buscamos contribuir com o processo de emancipação dessas mulheres camponesas, compreendendo a emancipação feminina imersa na perspectiva freiriana, em que a emancipação humana aparece "[...] como uma grande conquista política a ser efetivada pela práxis humana, na luta ininterrupta a favor da libertação das pessoas de suas vidas desumanizadas pela opressão e dominação social" (MOREIRA, 2010, p. 145). Baseado na perspectiva apresentada no todo da obra de Paulo Freire, esse autor reconhece que a educação sozinha não constrói uma sociedade emancipada; no entanto, 
[...] o trabalho de formação da educação popular também deve exercitar processos de emancipação individual e coletiva, estimulando e possibilitando a intervenção no mundo, a partir de um sonho ético-político da superação da realidade injusta. Tal intervenção se dá num fazer cotidiano e também histórico, atravessado de desafios, utopias, sonhos, resistências e possibilidades. (op. cit., p. 146).

É também dessa forma que entendemos a luta das mulheres por emancipação e liberdade, na importância do caráter pedagógico do processo educativo. Por isso, defendemos a construção de uma educação popular de caráter feminista, que incorpore as demandas das mulheres a partir do reconhecimento da estrutura de poder patriarcal historicamente construída e à qual foram subjugadas.

$\mathrm{O}$ artesanato funciona aqui como um importante espaço de formação coletiva em que são encaminhadas - além das oficinas de artesanato enquanto proposta inicial - outras atividades de formação na área de gênero como filmes, palestras, debates etc., nas quais o envolvimento feminino pode se repensar a partir do conhecimento da trajetória das mulheres no mundo e na história. Dessa forma, ao longo do tempo, foram se estabelecendo vínculos de confiança e afeto entre as pesquisadoras envolvidas e o grupo de agricultoras, em que se ampliou a possibilidade de trabalharmos questões polêmicas e delicadas quanto a gênero, violência contra a mulher, saúde da mulher, trabalho feminino, espaço público e privado, maternidade e conjugalidade, entre outros temas.

Essa experiência faz parte dos estudos de pós-doutoramento na área de Educação que tem sido realizado pela autora. Este texto tem o objetivo de apresentar alguns elementos da caminhada realizada até aqui com o grupo de mulheres camponesas, não percebendo essa trajetória de forma isolada, mas, sim, aliada a um processo de construção de um pensamento feminista latino-americano decolonial, tendo os saberes dos povos e movimentos sociais do Sul como parâmetros e o protagonismo das mulheres como motivação.

Inicialmente, o texto traz os referenciais teóricos utilizados, focando em suas principais contribuições para a pesquisa. Com essa intencionalidade, alguns conceitos são trazidos aqui, como patriarcado e pedagogia feminista popular, numa perspectiva epistemológica decolonial, em diálogo com as narrativas advindas das trajetórias de vida das mulheres camponesas. $\mathrm{Na}$ sequência, são apresentados e problematizados alguns dados coletados na experiência investigativa realizada com as mulheres camponesas, salientando aspectos de suas trajetórias autobiográficas de vida que afloraram nas narrativas faladas e bordadas. Por fim, nas Considerações Finais, busca-se uma articulação mais ampla da pesquisa específica realizada com a construção de um pensamento decolonial feminista. 


\section{Aproximações teóricas}

Christine Delphy (2009) define três sentidos históricos para a palavra patriarcado. O primeiro deles está vinculado a preceitos religiosos, quando o termo patriarca se referia a membros da Igreja ortodoxa. O segundo sentido está relacionado à área do Direito, quando é dado poder ao pai, no sentido de legitimação jurídica de autoridade. Nesse sentido,

[...] antes das denúncias dos autores socialistas, encontra-se bastante o adjetivo 'patriarcal' em autores do século XIX, utilizado de maneira elogiosa em expressões como 'as virtudes patriarcais', a saber, a simplicidade dos costumes, a frugalidade, a vida no campo. (op. cit., p. 174)

Provavelmente o terceiro sentido começa a se delinear a partir de escritos socialistas, como a obra de Engels: A origem da família, da propriedade privada e do Estado, publicada originalmente em 1884. Para Delphy (2009), apenas ganha força no feminismo contemporâneo, tendo a obra Política Sexual (1971), de Kate Millet, se tornado emblemática. Assim se desenvolve o sentido feminista do termo patriarcado, pois se refere a toda uma dinâmica de construção social e familiar na qual o homem (enquanto patriarca) submete todas as outras pessoas da família ao seu poder, especialmente as mulheres, incluindo também os filhos homens. O sentido feminista do termo prevaleceu, e hoje se compreende amplamente que o termo representa uma relação de poder que, hierarquicamente, confere mais poder aos homens do que às mulheres, não apenas na família, mas no todo social. Delphy (2009) ainda salienta dois aspectos característicos do patriarcado: por um lado, ele representa um amplo sistema e não fica restrito ao âmbito individual; por outro, as feministas denunciaram a relação entre o patriarcado com o capitalismo, estabelecendo suas diferenças, mas também denunciando suas conexões.

Sobre o patriarcado, Heleieth Saffioti constitui uma referência incontornável. Conhecida como a autora da primeira tese feminista defendida no Brasil, no início da década de 1970, já afirmava a importância da indissociabilidade entre gênero, classe e raça, o que atualmente denominamos interseccionalidade. Saffioti (1987, 2004, 2013), durante toda a sua vida, dedicou-se a caracterizar o patriarcado e denunciar sua violência intrínseca.

Na manutenção do patriarcado, sabemos que este sustenta um caráter pedagógico que lhe garante sua hegemonia. Sobre essa construção pedagógica, percebemos que 
O que precisamos significativamente é avançar na compreensão do aspecto ideológico de propagação do patriarcado, suas ferramentas de inserção e de reprodução que fazem com que as próprias mulheres, ainda que não sejam machistas, pois não possuem privilégios masculinos, passem a perpetrar e a reproduzir ações sexistas umas com as outras. (LOPES; SILVA, 2016, p. 264)

Para isso, é fundamental uma teoria educacional que incorpore as demandas de gênero e incorpore o que o pensamento feminista construiu. Dessa forma, defendemos a ideia de uma pedagogia feminista alicerçada nas bases da educação popular. Sabemos que a pedagogia feminista, de cunho popular, não é algo totalmente novo. Faz tempo que sabemos da existência de inúmeras experiências populares realizadas com grupos de mulheres - nossa experiência com mulheres assentadas do MST é uma delas. No entanto, o que vemos de forma recorrente são inúmeras iniciativas educativas realizadas em espaços não formais de educação que se organizam como práticas de oficinas, rodas de conversa e outras atividades pedagógicas que, por diversas vezes, carecem de uma reflexão teórica mais aprofundada que aponte para a construção de uma teoria feminista latino-americana de educação. Assim, é fundamental que se sistematizem essas experiências, de forma a se construir uma base teórica, metodológica e epistemológica de uma pedagogia feminista de caráter popular. Dessa forma, este artigo tem como objetivo sistematizar teoricamente uma experiência de educação popular baseada em oficinas, tendo utilizado como metodologia a coleta de dados empíricos por meio de narrativas autobiográficas.

Algumas construções importantes já apontam para a construção de uma pedagogia feminista e têm dado enormes contribuições nesse sentido, caso da obra da mexicana Ochoa (2008), que procura alicerçar as bases antropológicas, epistemológicas, teóricas e metodológicas para a construção do que denomina de pedagogia feminista. Outra contribuição significativa vem da trajetória da Rede de Educação Popular entre Mulheres (REPEM) ${ }^{1}$, como parte do Conselho de Educação de Adultos da América Latina (CEAAL). Presente em diversos países latino-americanos e caribenhos, conta com mais de 60 organizações; tem contribuído para o desenvolvimento do pensamento e da prática de educação popular na América Latina e Caribe e constituído importante espaço de formação política e luta das mulheres, buscando consolidar a perspectiva da educação popular feminista na região. Na Argentina, podemos citar a trajetória do grupo de educadoras populares, chamado Pañuelos en Rebeldía, que também aposta no legado da educação popular para a construção da pedagogia popular feminista. Enfim, podemos afirmar que, com termos e trajetórias um tanto diferentes, vislumbramos, em diversos países latino-americanos, algumas construções pedagógicas importantes de educação

${ }^{1}$ http://www.repem.org/. 
popular aliadas ao feminismo. Essas construções são exemplos inspiradores para nosso trabalho.

O conceito de situações-limite desenvolvido por Freire (2011) pode auxiliar na compreensão da materialidade que o patriarcado assume, pois ele é a situação-limite imposta às mulheres. Para ele, as situações-limite são aquelas entendidas pelos indivíduos como inevitáveis, constituintes da vida em sociedade, normatizadas e naturalizadas no cotidiano da vida social. É dessa forma que percebemos o patriarcado, em sua interseccionalidade com o racismo e o capitalismo como seus grandes aliados.

Para superarmos essa construção, precisamos construir formas de percebido-destacado, que nada mais são do que o processo de consciência que deve resultar no inédito-viável enquanto construção efetiva de um processo de transformação social emancipatória (ROSA; SILVA, 2017). Um elemento fundamental para essa tomada de consciência de gênero está na construção de uma sororidade entre as mulheres. Para Lagarde y de Los Ríos (2016), sororidade nada mais é do que uma aliança feminista entre as mulheres. É o apontamento de uma consciência crítica que surge de um processo coletivo de solidariedade entre as mulheres. Portanto, não é um processo individual, mas, sim, uma caminhada coletiva de compromisso das mulheres com seu próprio processo emancipatório e de libertação.

É a partir dessas compreensões que podemos avançar na construção de uma educação feminista, com base popular, comprometida com os interesses de classe de uma grande parcela de mulheres que estão alijadas das estruturas de poder e, mais do que isso, estão submetidas, de forma violenta e cruel, a essas estruturas. Essa construção deve ser pensada pelo Sul e para o Sul, de forma que as mulheres latino-americanas sejam protagonistas, não apenas como sujeitas das ações, mas como construtoras de conhecimento. Dessa forma, podemos pensar que

As perspectivas e as condições da subalternidade latino-americana, através da busca por teorizar a "experiência", o "conhecimento situado" e a "localização", como também ao questionarem estruturas e conceitos previamente e "racionalmente" definidos por um projeto moderno ocidental, no entendimento e interpretação aqui defendidos, buscariam se articular hoje como projetos epistemológicos alternativos, repensando (e negando algumas vezes) o diálogo com o Norte global e recuperando ou criando novos e outros diálogos a partir do Sul global. (CYPRIANO, 2013, p. 18).

Antes de demarcarmos nossa compreensão do termo decolonialidade, é preciso que se defina o nosso entendimento de colonialidade. A colonialidade do poder é um conceito desenvolvido originalmente por Aníbal Quijano, na década de 1980, e significa que as relações de colonialidade nas esferas econômica e política não terminaram com o final do colonialismo. O conceito possui uma dupla pretensão: de um lado, denuncia a continuidade das formas coloniais de dominação após as administrações coloniais, produzidas pelas culturas coloniais e 
pelas estruturas do sistema capitalista moderno/colonial; de outro, possui uma capacidade explicativa que atualiza e contemporiza processos que supostamente teriam sido apagados, assimilados ou superados pela modernidade, pois articula os lugares periféricos da divisão internacional do trabalho com a hierarquia étnico-racial mundial. Os povos não europeus vivem hoje sob o regime de uma colonialidade global imposta pelos países hegemônicos do sistema de acumulação, à frente os Estados Unidos, por meio do Fundo Monetário Internacional, do Banco Mundial, do Pentágono e da OTAN. As zonas periféricas mantêm-se numa situação colonial, ainda que já não estejam sujeitas a uma administração colonial. (BALLESTRIN, 2013)

Segundo Quijano (2005), a América constitui-se como o primeiro espaço/tempo de um padrão de poder mundial no qual dois processos históricos convergiram e se associaram na construção de um processo que o autor vai denominar colonialidade do poder. Por um lado, teremos a construção de diferenças entre conquistadores e conquistados consolidadas na ideia de raça, por sua vez alicerçada numa suposta distinta estrutura biológica que situava a população nativa em uma situação de inferioridade 'natural' em relação aos europeus colonizadores. Esse pensamento foi assumido pelos conquistadores e se torna a principal base de sustentação das relações de dominação impostas. Foi a partir desse alicerce que se classificou toda a população da América e, mais tarde, do mundo nesse novo padrão de poder. Por outro lado, e somada a isso, teremos a articulação das formas de controle dos processos de trabalho, de seus recursos e de seus produtos em torno do capital e do mercado mundial.

Dessa forma, na América a noção de raça foi uma maneira de legitimar as relações de dominação impostas pela conquista. A expansão do colonialismo europeu conduziu à elaboração da perspectiva eurocêntrica do conhecimento e, com ela, à elaboração teórica da ideia de raça como naturalização dessas relações coloniais de dominação entre europeus e não europeus, o que significou uma nova maneira de legitimar as práticas de relações de superioridade/inferioridade entre dominantes e dominados. Esse pensamento demonstrou ser o mais eficaz e durável instrumento de dominação social universal, pois os povos conquistados e dominados foram postos numa situação natural de inferioridade, incluindo seus traços físicos, suas capacidades mentais e intelectuais e seus traços culturais. Nos termos de Quijano (2005, p. 118), 
As novas identidades históricas produzidas sobre a ideia de raça foram associadas à natureza dos papéis e lugares na nova estrutura global de controle do trabalho. Assim, ambos os elementos, raça e divisão do trabalho, foram estruturalmente associados e reforçando-se mutuamente, apesar de que nenhum dos dois era necessariamente dependente do outro para existir ou para transformar-se.

Pensamos que o processo de decolonização não deve ser confundido com a rejeição de toda a construção que venha do Norte e diretamente associado com aquilo que seria genuinamente criado no Sul, no que se refere a experiências, conceitos, pensamentos e práticas. A decolonialidade pode ser vista como um contraponto e uma resposta à tendência de construção da ciência baseada no eurocentrismo. Atualmente, diversos autores e autoras, situados tanto nos centros quanto nas periferias da produção da geopolítica do conhecimento questionam o universalismo etnocêntrico e o eurocentrismo teórico contidos no mainstream das ciências sociais. Essa busca tem informado um conjunto de elaborações denominadas teorias e epistemologias do Sul, as quais procuram valorizar e descobrir perspectivas para a decolonização das ciências sociais. (BALLESTRIN, 2013, p. 109)

Sabemos que as mulheres latino-americanas pertencentes aos povos tradicionais formaram um grupo social em que o processo de exclusão foi e tem sido dos mais violentos. Dados atuais sobre violência contra as mulheres mostram que as mulheres do Sul estão bem mais expostas à violência. $\mathrm{O}$ padrão eurocentrista de gênero e feminilidade, aliado ao capitalismo e sob a égide do patriarcado, são nefastos para as mulheres do Sul. E esse processo histórico se constrói alicerçado na colonialidade do poder. A respeito do colonialismo europeu como um elemento que causou profundas marcas na América Latina e que coloca desafios para a construção de um feminismo latino-americano, Gargallo (2007, p. 22) salienta:

Para el feminismo latinoamericano es muy difícil deconstruir su occidentalidad,
porque ésta se impuso como sinónimo de un mundo tecnológicamente moderno y
legalista que hasta las socialistas querían alcanzar. Sólo desde el análisis de la pobreza
y la desigualdad como frutos de un colonialismo capitalista que necesitaba, y sigue
necesitando, de la contraparte pobre de la riqueza de su lugar de origen y expansión,
el feminismo latinoamericano se plantea hoy la necesidad de liberarse de la
perspectiva del universalismo cultural occidental, y su construcción determinista: la
organización de géneros sexuales, masculino y femenino, bipolares, binarios y
jerarquizados para que el trabajo gratuito de las mujeres descanse en una naturaleza
invariable, construida desde la cultura.

A autora aproxima o processo de colonização com o patriarcado ao afirmar que o processo de superioridade masculina é uma complexa construção cultural que possui características parecidas com o "racismo de la conquista y a la esclavización de los vencidos, de tal forma que sistema de géneros y guerra, sistema de géneros y colo- nialismo se acompañan y refuerzan uno a otro, porque tienen un mecanismo de jerarquización común en su base.” (op. cit., p. 24). 
Dessa forma, nossa pesquisa situa-se no compromisso de contribuir na construção de uma epistemologia do Sul, a partir das experiências e narrativas das mulheres camponesas vinculadas ao MST.

\section{As trajetórias faladas e bordadas}

No que se refere ao uso de narrativas na pesquisa, a metodologia adotada parte da produção da pesquisa participante e adota a história de vida como instrumento metodológico advindo da pesquisa-formação. A proposta de se compreender o processo de investigação como um "caminhar para si", de acordo com a ideia de Josso (2004), mostra o processo de inacabamento da pesquisa, ao mesmo tempo que nos remete às nossas próprias trajetórias de vida no mundo. A ideia de conhecermos a nós mesmas não significa apenas entender como nos formamos individualmente; trata-se, para além disso, de nos reconhecermos como sujeitos sociais, tornando-nos mulheres emancipadas em nossa existência.

Em texto anterior, elaborado em parceria, já explicitávamos essa intenção ao afirmar que

As experiências individuais das mulheres artesãs funcionaram nessa investigação como pano de fundo para a análise de situações mais abrangentes de enfrentamento ou submissão à lógica, tanto do capital quanto do patriarcado. Isso não menospreza de forma alguma as experiências específicas das artesãs envolvidas na pesquisa. Pelo contrário, as narrativas abordadas aqui materializam as experiências de inúmeras mulheres, extrapolando o espaço privado e visibilizando uma diversidade de situações que não são nada individuais nem privadas. Trata-se de um processo de "coletivizar" as experiências femininas. (EGGERT; SILVA, 2011, p. 61).

Dessa forma, nos aliamos a perspectiva defendida por Marín (2013), da recuperação coletiva da história, surgida na América Latina nos anos setenta do século XX, ancorada nas concepções da corrente metodológica da investigação-ação-participativa (Orlando Fals Borda) e da educação popular (Paulo Freire). A recuperação coletiva trabalha as perspectivas de produção de conhecimento, a partir de diversos saberes no interior de setores populares e movimentos sociais, resgatados a partir da memória. Reconhecemos como uma contribuição na construção de uma epistemologia decolonial de conhecimento, que possui como objetivos principais, além da ordem metodológica citada acima, um caráter político, pois incorporou categorias advindas do marxismo e da filosofia e teologia da libertação, sofrendo dessas forte influência. Dessa forma, conforme afirma Marín (2013, p.102), 
Dado que uno de los propósitos centrales expuestos por la recuperación colectiva de la historia fue visibilizar la no inclusión en la "historia nacional" de aquellas historias que habían sido previamente subalternizadas, resulta necesario analizar desde las herramientas teóricas que nos brinda la colonialidad, en la agencialidad de dichas historias, como también de sus actores, ya no sólo en términos de su inclusión sino como "lugares" epistémicos de producción de conocimiento.

Assim, compreendemos a experiência com as mulheres assentadas como lugares epistêmicos de produção de conhecimento, que podem contribuir num processo de recuperação coletiva da história, na construção de uma outra epistemologia. Quanto ao uso do artesanato, as mulheres, historicamente, possuem uma aproximação e um vínculo muito forte com os chamados trabalhos manuais. Mesmo na atualidade, com a manualidade sendo suplantada pela produção capitalista mecanizada de massa, muitas mulheres seguem a herança de suas antepassadas e têm na produção manual advinda do artesanato seu sustento, compondo um contexto e um conhecimento pouco analisado pela ciência. Essa construção de conhecimento é uma atividade laboral, de trabalho que, muitas vezes, é invisibilizada pelas próprias mulheres. Há tempos pesquisando esse contexto, não é raro nos depararmos com mulheres que, sustentando suas famílias com a comercialização da produção artesanal, afirmam que 'não trabalham', pois, como estão fora do trabalho na lógica do capital, não se percebem como trabalhadoras.

Dentre as diversas atividades realizadas, as mulheres participantes foram desafiadas a construir suas trajetórias em bordados. Dessa forma, trajetórias e resgates de memórias aparecem não apenas na oralidade, mas na própria produção artesanal. Essa experiência se constituiu na primeira pesquisa de pós-graduação em educação realizada com as mulheres assentadas, participantes desse projeto, pela qual as agricultoras narraram suas histórias de vida na técnica de bordado chileno, denominado arpillera $^{2}$. Assim, a atividade proposta, que deu origem à dissertação de Godinho (2017), provocou-as a confeccionarem suas trajetórias de vida de forma estética, a partir da prática de bordar, em conjunto com as narrativas orais e escritas.

Lonita é um nome fictício de uma assentada que participou da proposta de narrativa bordada, feita, na época, pela Mestranda em Educação, Eliane Godinho. Ela é uma assentada que participou da fase de acampamento, situação que não fez parte da trajetória de todas as mulheres do grupo. Nesse caso, Lonita fez questão de retratar esse momento em seu bordado,

\footnotetext{
2 Segundo GODINHO e SILVA (2017), Arpilharia ou Arpillera é uma técnica têxtil chilena que possui raízes numa antiga tradição popular iniciada por um grupo de bordadeiras de Isla Negra, no litoral central chileno. As arpilleras originais eram montadas em suporte de aniagem, pano rústico proveniente de sacos de farinha ou de batata, geralmente fabricados em cânhamo ou linho grosso, por nós mais conhecido como juta. Toda a costura é feita à mão, utilizando agulhas e fios. Importante ressaltar que, nos primórdios dessa construção, as primeiras bordadeiras usavam como tecido para os bordados as roupas dos seus familiares, desaparecidos políticos, no período da ditadura chilena. Por isso, produzem um trabalho que não só é uma peça artesanal com fins estéticos, mas uma forma de expressão popular, de luta, de resistência e, muitas vezes, de denúncia - por isso o seu caráter político.
} 
no qual é visível o barraco de lona preta. A família aparece em destaque, o que demonstra a importância dessa instituição social na trajetória de vida dessa mulher. Outro destaque possível se refere ao pano bordado como um todo. É possível perceber que o quadro parece dividido em duas partes que representam tempos diferentes: do lado esquerdo, é destacada a fase de acampamento, em que aparece, além das lonas pretas que representam as moradias provisórias, típicas da fase inicial de ocupação, a terra, ainda sem produção sobre ela; na parte direita do quadro, aparecem moradias fixas, típicas da fase de assentamento, e sobre a terra aparece a produção agrícola, materializada em plantação de abóboras.

A seguir, apresentamos um pequeno trecho do depoimento de Lonita (2016) sobre seus sentimentos no tocante ao exercício de bordar sua história de vida:

Este bordado significou a nossa história de vida. Foi muito importante contar a minha história de vida e trabalho em grupo. Conseguimos levar nossa história de luta adiante, resgatando a nossa origem, contando sobre a nossa alimentação, nosso trabalho e o cuidado dos filhos. Nossa luta pela terra foi muito importante, mudou a minha vida ficar acampada nove meses, assim conseguimos conquistar nossa terra, minha casa, plantando, participando da organização do assentamento com meu marido e meus três filhos. [...] No meu bordado, bordei a minha história, minha luta pela terra. Do tempo vivido na lona preta e da vida no acampamento em Santo Antônio das Missões - perto de Carazinho - RS. Fiz parte da frente de trabalho em Vacaria, na colheita da maçã, era cozinheira e cozinhava para dezoito pessoas, nesse tempo fomos sorteados para o assentamento. [...] Bordar o meu lote e contar um pouco da minha história é importante para registrar como é bom ter a minha propriedade junto com a minha família e dela poder retirar os frutos para nosso sustento e alimentação. Passando coisas boas para outras pessoas. No meu lote cuido da horta, planto milho, feijão, faço todo tipo de serviço. Também faço parte da Feira da Reforma Agrária em Pinheiro Machado, a cada quinze dias comercializo meus produtos, levando verduras, doces, hortaliças livres de veneno e meus artesanatos. Participo do grupo da Bionatur, plantando e cultivando sementes orgânicas. Graças à minha fé estou aqui e agradeço a Deus a oportunidade de superar as dificuldades e poder contar a minha história a outras mulheres para que não deixem de sonhar e lutar pelo que acreditam.

O ingresso de Lonita no MST implicou deslocamento, pois o assentamento se deu em outra localidade, o que exigia transferência da família para começar a vida em outro lugar. Sobre a chegada ao local de assentamento, Lonita disse:

\begin{abstract}
Nossa chegada foi muito difícil, viemos de ônibus com as crianças, trazendo só as bolsas e as crianças. Ficamos um ano embaixo do barraco de lona preta, construímos nosso barraco buscando as varas (galhos) nos matos, das tarimbas de taquara, fizemos os móveis, enquanto isso aguardava a vinda dos recursos do INCRA. Começamos a plantar fazendo terra a boi e a enxada, com foice, roçando. Na época tinha uma filha de quatro anos e um menino de três, eles cresceram no assentamento, enfrentamos muitas dificuldades. Hoje cada um já tem sua família, o meu filho também tem um lote no assentamento e ele mora em outro município. Com o tempo tivemos outro filho, ele tem oito anos, temos três netos que vem nos visitar e é sempre muito bom.
\end{abstract}

É possível perceber que a trajetória de vida bordada e narrada por Lonita carrega uma série de significados, especialmente no tocante às trajetórias de vida das mulheres assentadas. Importante destacar que esse relato se aproxima muito dos relatos das demais participantes, nos 
quais é visível a presença de suas famílias e da luta pela terra nos depoimentos e também nos bordados confeccionados. De modo geral, podemos afirmar que categorias importantes dos estudos de gênero estão presentes nas narrativas como família, maternidade, trabalho, espaço doméstico e religiosidade.

Lonita possui orgulho por ter participado ativamente do processo de luta pela terra. Salienta as diversas dificuldades pelas quais passou para chegar até o momento atual de sua vida, em que consegue produzir seu alimento, produzir um excedente que comercializa, confeccionar e vender o artesanato que produz. Nessa trajetória, podemos perceber o grande acúmulo de trabalho de uma mulher que assume todo o trabalho doméstico e mais as atividades típicas de produção agrária e de comercialização, reproduzindo aspectos típicos do patriarcado. Ao longo de nossa experiência acadêmica e de convivência com o grupo tem sido possível perceber o quanto essas mulheres estão submetidas a um processo forte de divisão sexual do trabalho. Na sequência, abordamos melhor esse aspecto, que aparece de forma tão latente na história de vida de Organza.

\section{A mulher e a lida do campo: a divisão sexual do trabalho marca a vida das camponesas.}

Investigar as trajetórias de vida das mulheres e seus saberes não é apenas um simples exercício de resgate de memórias individuais, uma mera releitura de suas vidas (embora apenas isso já poderia ser capaz de despertar para novas perspectivas), mas é de fato problematizar a opressão que vivemos em relação ao mundo do trabalho.

Uma das opressões mais importantes e profundas às quais são submetidas as mulheres se refere ao mundo do trabalho, mais especificamente a um processo chamado de divisão sexual do trabalho, que resulta

[...] de um sistema patriarcal capitalista que, por meio da divisão sexual hierárquica entre os sexos, confere às mulheres um baixo prestígio social e as submete aos trabalhos mais precarizados e desvalorizados. Há, portanto, uma determinação social e não natural para a existência da divisão sexual do trabalho (CISNE, 2015, p.117118).

No modo de vida rural, essas desigualdades podem ser mais invisibilizadas do que nas áreas urbanas e, ao mesmo tempo, mais aprofundadas. No campo, os espaços público e privado são mais mesclados, o que dá um caráter difuso ao trabalho que, no caso das mulheres, se soma ao processo de naturalização do trabalho doméstico que, historicamente, tem sido considerado como tarefas referentes aos papéis sociais feminimos. No trecho do depoimento apresentado a seguir, uma das camponesas que participou da pesquisa declarou o seguinte sobre suas memórias de infância e juventude: 
[...] o que eu lembro que com 7 anos eu já trabalhava na roça antes de ir para escola, primeiro eu capinava com meus irmão porque a escola era perto da minha casa, meu pai dizia que não podia ir muito cedo pra escola que era só pra brincar. Então, minha infância foi assim, não lembro de ganhar nenhum brinquedo, brincava com pedaço de prato, de xicara, boneca era de pano que a gente enrolava num pedaço de pano ou qualquer coisa que tinha, pra sair brincar com as outras crianças. Com 11 anos, a minha irmã mais velha casou e eu fiquei tomando conta da casa, cozinhava, limpava e lavava roupa, quase não tinha tempo para brincar. Com 12 anos parei de estudar, na escola que ia era só até a 4a série, as outras escolas eram longe, então meu pai não deixou eu continuar a estudar, eu lembro que eu chorei muito porque gostava de estudar, então quando eu tinha tempo eu brincava de ir na escola de baixo das árvores. (Organza, 2016)

Nesta passagem, fica explicitada a dimensão que o trabalho tomou na vida dessa mulher camponesa, desde tenra idade. No entanto, esse processo de naturalização faz com que a sobrecarga de trabalho feminino passe despercebido, além de invisilibizar e menosprezar o trabalho realizado pelas mulheres no espaço doméstico. Também chama a atenção o afastamento da escola, atrelado diretamente ao processo de exploração da força de trabalho de Organza.

$\mathrm{Na}$ sequência, a mesma camponesa mostra o seu ingresso na fase adulta. Estrategicamente, ela soube utilizar o próprio trabalho como justificativa para se libertar da dureza da figura paterna e do trabalho pesado ao qual era submetida.

Com 19 anos eu queria muito ir morar com meu irmão em Novo Hamburgo, primas também moravam lá, então meu irmão conseguiu que o pai deixasse eu ir morar com ele, então me livrei do serviço mais pesado e do comando mais rígido dos meus pais. Então, comecei a trabalhar pra mim [...] (Organza, 2016).

\section{Mulheres no/do movimento}

Na pesquisa realizada Godinho (2017) com as mulheres assentadas, também houve destaque para o processo de luta pela terra no movimento social, que envolveu a mudança de lugar, a dificuldade de adaptação, etc.

Sinto que bordei a minha vida nesta tela, porque é muito importante para mim ter um lugar onde eu possa ter animais, a minha casa, o meu lote, a minha horta, ter o meu lar. Antes do assentamento aqui só tinha quase fazendeiros, mas com o passar do tempo isso foi mudando e claro que ainda tem. E também tem gente que ainda fala mal de nós, mas são pessoas que não entendem nossa luta. Pois foi com a nossa chegada no município que a cidade começou a melhorar e a evoluir. O lugar onde temos a nossa casa era chão de mato, não tinha banheiro, mas quando a nossa casa veio ela tinha banheiro, quanta coisa veio quebrada, quando mudança chegou, tudo estava estragado. Quando cheguei aqui em 1997 me deu um desespero, era tudo mato, chorei muito debaixo da lona preta, levamos um ano para ganhar a nossa casa. Começamos a lidar na terra e plantar. Hoje temos de tudo! (Seda, 2016). 
No entanto, de forma diferente do que poderíamos supor em uma sociedade capitalista que, como sabemos, tem como parâmetros o incentivo ao individualismo, a competição e o consumismo, as histórias dessas mulheres são marcadas por uma perspectiva coletiva desenvolvida no processo de luta política do MST pela reforma agrária no Brasil. Em seus depoimentos ficam evidentes o caráter coletivo de suas lutas e o orgulho de participarem desse movimento social. Esse aspecto não advém simplesmente da posse da terra no seu sentido individual, como se poderia supor, mas na construção coletiva do movimento social ao qual pertencem. Além disso, a preocupação de trabalhar com sementes orgânicas demonstra uma preocupação ecológica com a preservação do meio ambiente, resultado de uma formação em agroecologia.

Dessa forma, o exercício do bordado, além de materializar um processo de ensinoaprendizagem (pois nenhuma das mulheres conhecia essa técnica de bordado antes dessa atividade), serviu como um gatilho que detonou o processo de revisitação de suas próprias memórias e trajetórias. Desse modo, foi possível que as mulheres participantes revisitassem suas memórias e resgatassem suas lembranças, mas não de forma estanque e estática, e sim de forma ressignificada, com a soma da experiência criada com e no grupo. No momento, encontra-se em fase de execução a segunda pesquisa de mestrado em educação com o grupo.

Saliente-se também, por fim, o fato de que, atualmente, as mulheres constituíram um grupo associativo autônomo e realizaram oficinas de artesanato na universidade, passando de aprendentes a educadoras, tornando-se multiplicadoras do processo do qual fazem parte. Assim, pensamos que é possível a construção e o fortalecimento de um feminismo comunitário, conforme defende a feminista Julieta Paredes (2017). Na defesa dos direitos das mulheres indígenas colombianas, Paredes denuncia a invisibilidade das mulheres, pois quando estão em defesa políticas públicas para o campesinato, para a saúde, para a educação e para as mulheres, transparece que as mulheres estão fora desses espaços. Essas compreensões reforçam sua invisibilidade, como a expressa Paredes (2017, p. 111):

Otra forma de ejemplificar esto es cuando se habla de qué se va a tratar el tema del transporte, la seguridad ciudadana, la economía, los recursos naturales y el tema de la mujer, como si nosotras como mujeres no tuviéramos que ver con el tema del transporte, la seguridad ciudadana, la economía y los recursos naturales. (PAREDES, 2017, p. 111)

Ocorre então que, mais do que invisibilizar as mulheres e sua participação nos espaços sociais, esse pensamento materializa a representação da mulher vista como um problema social a ser resolvido, assim como os outros citados. É ainda Paredes que mostra o quanto esse processo, mantido por um colonialismo tanto externo quanto interno (aos diversos países), 
desenvolve e mantém uma representação vazada num imaginário ético e estético baseado em valores eurocentristas, do qual não apenas as mulheres indígenas às quais Paredes se refere, mas também as mulheres campesinas que temos acompanhado não fazem parte.

Sobre a experiência das oficinas que implementamos com as mulheres camponesas no Brasil, a narrativa apresentada a seguir trata do assunto, quando Sarja diz que

Esse foi um passo que nós conquistamos juntas e podemos chegar mais longe, se nos unirmos [...] Teremos que ser mulher para enfrentar nossos problemas ou o que seremos então?... Eu debato todas as noites com meu companheiro sobre o artesanato e as viagens. Sempre digo pra ele: liberdade para os dois. (Sarja)

Sobre as viagens que ela trata no depoimento, se refere às suas idas a diversos eventos e feiras, nos quais elas, em função e sua participação no projeto, passaram a ser convidadas a participar.

\section{Considerações finais}

$\mathrm{Na}$ trajetória construída com as mulheres assentadas, o artesanato tem possibilitado a construção de um espaço-tempo de formação coletiva e de construção de conhecimento que extrapola o mero aprendizado de técnicas em artesanato, mas incluindo uma formação política e feminista. Nesse ambiente, criou-se um espaço para a problematização de diversos temas de gênero no qual antes não havia a possibilidade dessas aprendizagens coletivas em que questões feministas pudessem vir à tona.

É importante salientar a postura que a equipe da universidade procura ter com as mulheres envolvidas, reconhecendo seus saberes e incorporando seus desejos e opiniões em todo o processo. Partimos do conhecimento delas, jamais impondo nosso olhar sobre o grupo e, sim, construindo em conjunto com elas a caminhada. Trata-se de uma perspectiva de conhecimento na qual o diálogo entre os diversos saberes são uma constante. Essas atitudes remetem a outra forma de fazer ciência, a outra maneira de produção de conhecimento; uma forma pautada na decolonização e na perspectiva de valorização das culturas dos povos tradicionais, no caso, das mulheres do campo.

Sendo assim, é possível afirmarmos que foi nesse espaço de tempo de construções artesanais e coletivas, entre as tramas das linhas, dos tecidos e de diversas matérias-primas do mundo artesanal que as narrativas trouxeram à tona a força e a potência das histórias de vida que, mais do que individuais, visibilizaram a coletividade das construções históricas do mundo rural e da mulher camponesa. Foi revisitando as memórias que conseguimos compreender as 
cicatrizes das diversas trajetórias, marcadas pela opressão de gênero, pelo isolamento da vida do campo e pelo acúmulo do trabalho. E foi considerando e problematizando esses elementos que buscamos construir outras alternativas para todas. Afinal, elas não estão sós.

Portanto, é urgente que a produção acadêmica se revisite e desenvolva esforços na construção de uma ciência decolonial que incorpore as trajetórias históricas e de conhecimento dos diversos povos tradicionais, com especial atenção para a produção feminista latinoamericana. Nossa pequena intervenção se alia à construção dessa perspectiva.

\section{Referências}

BALLESTRIN, Luciana. América Latina e o giro decolonial. Revista Brasileira de Ciência Política, n. 11, Brasília, maio/ag. 2013. p. 89-117.

CISNE, Mirla. Gênero, divisão sexual do trabalho e serviço social. 2. ed. São Paulo: Outras Expressões, 2015.

CYPRIANO, Breno. Construções do pensamento feminista latinoamericano. Estudos Feministas, Florianópolis, v. 21, n. 1, jan.-abr., 2013. p. 11-39.

DELPHY, Christine. Patriarcado (Teorias do) [verbete]. In: HIRATA, Helena et al. (orgs.). Dicionário crítico do feminismo. São Paulo: Ed. UNESP, 2009. p. 173-178.

EGGERT, Edla; SILVA, Márcia Alves da. Observações sobre pesquisa autobiográfica na perspectiva da educação popular nos estudos de gênero. Contexto \& Educação, v. 26, n. 85, jan./jun. 2011. p. 51-68.

FREIRE, Paulo. Pedagogia do oprimido. Rio de Janeiro: Paz e Terra, 2011.

GARGALLO, Francesca. Feminismo latinoamericano. Revista Venezolana de Estudios de la Mujer, Caracas, v. 12, n. 28, enero/junio, 2007. p. 17-34.

GODINHO, Eliane. O "Artesanato de Si" de mulheres assentadas do MST: um processo político-pedagógico feminista pelo viés da educação popular. (Dissertação de Mestrado). Universidade Federal de Pelotas - Brasil. 2017.

GODINHO, Eliane; SILVA, Márcia Alves da. O trabalho de mulheres assentadas do MST retratado em arpilleras enquanto uma proposta pedagógica feminista. Documento apresentado no I Congresso Internacional de Memória e Educação: narrativas (auto)biográficas. Santa Maria, RS, Brasil, mar./abr. 2017.

JOSSO, Marie-Christine. Histórias de vida e formação. São Paulo: Cortez, 2004. LAGARDE Y DE LOS RÍOS, Marcela. Sororidad. In: CASTRO, Amanda e MACHADO, Rita (orgs.). Estudos feministas, mulheres e educação popular. Curitiba: CRV, 2016. p. 2533. 
LOPES, Daniele Rehling; SILVA, Márcia Alves da. Da educação não sexista à pedagogia feminista. In: CASTRO, Amanda; MACHADO, Rita de Cássia (orgs.). Estudos feministas, mulheres e educação popular. Curitiba: CRV, 2016. p. 263-275.

MACHADO, Rita (orgs.). Estudos feministas, mulheres e educação popular. Curitiba: CRV, 2016. p. 25-33.

MARÍN, Pilar Cuevas. Memória Colectiva: hacia um proyeto decolonial. In: WALSH, Catherine (org.). Pedagogías decoloniales: prácticas insurgents de resistir, (re)existir y (re)vivir. Tomo 1. Quito, Ecuador: Ediciones Abya-Yala, 2013. p. 69-103.

MOREIRA, Carlos Eduardo. Emancipação [verbete]. In: STRECK, Danilo; REDIN, Euclides; ZITKOSKI, Jamie José (orgs.). Dicionário Paulo Freire. 2. ed. Belo Horizonte: Autêntica, 2010. p. 145-146.

OCHOA, Luz Maceira. El sueño y la práctica de sí - Pedagogía feminista: una propuesta. México, D. F.: El Colegio de México, Centro de Estudios Sociológicos, Programa Interdisciplinario de Estudios de la Mujer, 2008.

PAREDES, Julieta. Hilando fino desde el feminismo comunitario. In: GUZMÁN, Alejandra de Santiago; BORJA, Edith Caballero; ORTUÑO, Gabriela González (orgs.). Mujeres intelectuales: feminismos y liberación en América latina y el Caribe. Buenos Aires: CLACSO, 2017. p. 111-140.

QUIJANO, Aníbal. Colonialidade do poder, eurocentrismo e América Latina. In: LANDER, Edgardo (org.). A colonialidade do saber: eurocentrismo e ciências sociais. Perspectivas latino-americanas. Buenos Aires: CLACSO, 2005. p. 117-142.

ROSA, Graziela Rinaldi da; SILVA, Márcia Alves da. Práticas educativas feministas no Brasil: perspectivas epistemológicas antipatriarcais e a pedagogia feminista. In: AMARO, Sarita; DURAND, Véronique (orgs.). Veias feministas: desafios e perspectivas para as mulheres do século 21. Rio de Janeiro: Bonecker, 2017.

SAFFIOTI, Heleieth. A mulher na sociedade de classes. 3. ed. São Paulo: Expressão Popular, 2013.

SAFFIOTI, Heleieth. Gênero, patriarcado e violência. São Paulo: Perseu Abramo, 2004.

SAFFIOTI, Heleieth. O poder do macho. São Paulo: Moderna, 1987.

SEGATO, Rita. La guerra contra las mujeres. Buenos Aires: Prometeo Libros, 2018. 